Institute of $\mathbf{F}_{\text {ood and }} \mathbf{A}_{\text {gricultural }} \mathbf{S}_{\text {ciences }}$

\title{
Manual de los Reglamentos del Agua de Florida: Sistemas de Tanques de Almacén de Contaminantes ${ }^{1}$
}

Michael T. Olexa, Laura Minton, Dulcy Miller, y Sarah Corbett ${ }^{2}$

\section{Agradecimientos}

Los autores agradecen a Richard Budell de la Oficina de Política del Agua Agrícola del Departamento de Agricultura y Servicios al Consumidor de Florida. Los autores también agradecen a David H. Hammonds, Consultor del Programa de Salud Ambiental, Oficina de Programas de Aguas de Drenaje en el Sitio, del Departamento de Salud de Florida, y a Edward A. Bettinger, Consultor del Programa de Salud Ambiental, Oficina de Programas de Agua del Departamento de Salud de Florida.

\section{¿Quien Regula el Sistema de Tanques de Almacén de Contaminantes?}

La regulación en todo el estado de los tanques estacionarios de almacén, es principalmente del dominio del Departamento de Protección Ambiental (DPA). El DPA tiene el poder de regular los tanques de almacén de contaminantes, a través del Acta de Control de Prevención de descargas Contaminantes. Consecuentemente, muchas de las reglas cubiertas en esta sección son aquellas del DPA. Es importante señalar, sin embargo, que las regulaciones permiten a los gobiernos de los condados individuales promulgar sus propias reglamentaciones. Esas reglamentaciones locales pueden ser mas estrictas que aquellas del DPA. Las autoridades del condado deben ser

1. Este es el documento EDIS FE086, una publicación del Department of Food and Resource Economics, Florida Cooperative Extension Service, Institute of Food and Agricultural Sciences, University of Florida, Gainesville, FL. Publicada Noviembre 2002. Por favor visite la página electrónica EDIS en http://edis.ifas.ufl.edu.

2. Michael T. Olexa, es profesor del Department of Food and Resource Economics, Florida Cooperative Extension Service, Institute of Food and Agricultural Sciences, University of Florida, Gainesville, FL; y miembro de Florida Bar; Presidente de Agricultural Law Committee of The Florida Bar; y Director del Agricultural Law Center. Laura Minton, Dulcy Miller, y Sarah Corbett son estudiantes graduadas de Levin College of Law, University of Florida, Gainesville, FL. Filiberto Reyes-Villanueva fue el traductor de la versión en ingles al español.

Esta publicación esta diseñada para proporcionar información precisa, actualizada y autorizada sobre esta material. Sin embargo, ya que las leyes, reglas administrativas y decisiones de la corte, sobre las cuales están basados, están sujetas a revisión constante; algunas partes de esta publicación podrían ser obsoletas en cualquier momento. Esta publicación es distribuida bajo el entendimiento que los autores no están involucrados en ninguna representación legal u otros servicios profesionales, y que la información contenida aquí no debe ser considerada como un substituto de una asesoria legal. Esta publicación no esta completa en proporcionar toda la información para lograr el cumplimiento de las leyes y reglamentos que gobiernan la protección del agua. Por estas razones, el uso de estos manuales por cualquier persona constituye un acuerdo para mantener libre de daño a los autores, al Florida Cooperative Extension Service, al Institute of Food and Agricultural Sciences, y a la University of Florida por cualquier demanda por responsabilidad de daños, o gastos en que pueda incurrir cualquier persona, como un resultado de hacer referencia o confianza sobre la información contenida en esta publicación. Esta publicación fue apoyada financieramente por el Florida Department of Agriculture and Consumer Services.

EI Instituto de Alimentos y Ciencias Agrícolas es Un empleador que opera bajo Acción Afirmativa y provee Oportunidades Igualitarias, dedicado a promocionar la investigación, a información educativa y otros servicios, únicamente a los individuos e instituciones que operan baj discriminación sin considerar color, raza, sexo, edad, incapacidad u origen. Para más información sobre como obtener otras publicaciones de la extensión, comuníquese con la oficina de Servicio de Extensión de su condado. Servicio de Extensión de la Florida / Instituto de Alimentos y Ciencias Agrícolas / Universidad de la Florida / Christine Taylor Waddill, Decana. 
consultadas sobre si la actividad o condición de los tanques de almacén están aparentemente dentro de los estándares del estado.

\section{¿Qué es un Contaminante?}

Un tanque caerá entro del campo de las reglamentaciones si tiene un contaminante. Un "contaminante" esta definido básicamente como:

- algún tipo de aceite o gasolina.

- algún plaguicida.

- algún compuesto de amonio o cloro o derivado, excluyendo gas liquido de petróleo.

\section{¿Cuáles Sistemas son Reglamentados?}

La mayor parte de las regulaciones solo se aplican a sistemas de tanques de almacén cuya capacidad es mayor de 110 galones. Los tanques mas pequeños que estos, solo necesitan cumplir con los requerimientos generales de que no descarguen sus contenidos en el medio ambiente y que sigan los estándares de prevención del fuego.

Hay una lista de 23 tipos de sistemas de tanques de almacén que están exentos en este Capitulo. Cualquier sistema de tanque de almacén agrícola de 550 galones o de menor capacidad esta exento. Para una lista mas extensa y actualizada revise con el DPA.

El DPA hace importantes distinciones entre tanques nuevos y aquellos que ya estaban en operación desde antes de 1992. Los nuevos tanques están sujetos a estrictos estándares de seguridad, pero los tanques existentes deben cumplir con muchos de los mismos estándares de protección de sobrellenado, sistemas de monitoreo y forrado de tanques dentro de un periodo determinado, El tiempo permitido que "ese ajuste retroactivo" varia dependiendo del año en que fue instalado el tanque, pero el DPA contempla tener el ajuste retroactivo de todos los tanques existentes para el 2009.

Los sistemas de superficie están sujetos a reglamentaciones menos estrictas y están sujetos a este Capitulo si ellos tienen una capacidad mayor que
550 galones. (Un tanque "sobre la superficie" no tiene mas del 10 por ciento de este volumen enterrado, incluyendo la tubería completa). Estos tanques, sin embargo están sujetos a reglas similares de mantenimiento delos registros, como los tanques enterrados y deben ser equipados con una barrera para colectar derrames. Además, cualquier parte del tanque en contacto con el suelo debe estar protegida contra la erosión.

\section{¿Qué Deben Hacer los Propietarios de los Sistemas?}

No hay requerimientos para permisos que se originen directamente del DPA o la reglamentación local para tanques. Sin embargo, los dueños de sistemas deben saber:

- registrar los tanque en el DPA 10 días antes de iniciar la instalación.

- notificar al DPA 30 días antes del cierre de algún sistema de tanque de almacén o 10 días antes que ocurra una reposición o reparación.

- notificar al DPA dentro de 30 días de un cambio en la propiedad de un sistema de tanque de almacén.

- reportar inmediatamente cualquier derrame que represente cualquier amenaza a la calidad del medio ambiente (esto incluye descargas en exceso de 100 galones en superficies permeables).

\section{¿Qué son la Construcción, Reparación y Probado de Estándares?}

Todos los tanques nuevos deben cumplir con una lista completa de requerimientos de seguridad, incluyendo la construcción reforzada o de doble pared, sistemas de monitoreo (incluyendo pozos de monitoreo), placas contra golpes, sistemas de aislamiento eléctrico y otras especificaciones. Similares requerimientos han sido promulgados para los sistemas de tubería usados en la conexión de los tanques. 
El DPA también exige requerimientos extensivos para probar la integridad de los tanques y para tomar muestras de los tanques, monitoreo de pozos y del suelo en la vecindad de un tanque. Todas las pruebas deben ser llevadas a cabo por personal entrenado. Aunque los intervalos delas pruebas están especificadas en las reglas, el DPA retiene la autoridad para completar el probado se sistemas donde quiera que crea necesario, en base a:

- fallas de operador para cumplir con las reglas.

- evidencia de una descarga o de contaminación en el área.

Los operadores de las instalaciones de almacenaje son requeridos para mantener registros de las inspecciones del DPA. Estos registros deben incluir los resultados de todas las pruebas e inspecciones, así como también el mantenimiento y notas de inventario sobre los tanques o sus contenidos. Los registros debe estar desde al menos dos años antes y deben estar disponibles para el DPA dentro de cinco días de trabajo después de la noticia.

\section{¿Cuáles son los Procedimientos y Precauciones de Limpieza?}

Los operadores pueden ser requeridos por las leyes federal y estatal para adoptar un Plan de Contramedida y Control Para Prevención de Derrames antes de la instalación de un tanque. Esto es de acuerdo a la política federal de monitorear cualquier cosa con el potencial de contaminar el medio ambiente a través descargas de petróleo. Este plan, o el plan alterno aprobado por el DPA, debe detallar el drenaje y otras medidas de ingeniería tomadas para mitigar el dañó de derrames y puede requerir por adelantado, de un compromiso escrito de los materiales y la mano de obra que será usada para limpiar cualquier derrame que ocurra.

Como se menciono antes, los derrames deben ser reportados inmediatamente y el propietario $\mathrm{u}$ operador deben tomar los pasos inmediatos para "contener, remover o disminuir la descarga". Si la calidad del agua subterránea esta amenazada por el derrame, el DPA puede ordenar también al dueño tomar cualquier acción que sea necesaria para reducir el daño publico.

\section{¿Cuál es el Procedimiento Apropiado para el Abandono de un Tanque?}

El procedimiento para el abandono de un tanque es:

1. Los tanques abandonados deben ser bombeados hacia fuera y limpiados mediante vapor.

2. Los tanques subterráneos necesitan o ser removidos del suelo, o bien pueden ser llenados con arena, concreto u otro material inerte.

3. Los tanques que son eliminados como chatarra deben ser perforados o inutilizados de cualquier otra manera.

4. Los tanques de petróleo que se intentan reutilizar deben ser claramente etiquetados como "no para uso de alimentos"

5. Ningún tanque abandonado puede ser usado para almacenar contaminares. Los tanques abandonados no pueden ser reutilizados a menos que sean completamente reconstruidos para cumplir con los estándares de tanques nuevos.

Bajo el Acta de responsabilidad, Compensación y Respuesta Ambiental Completa (ARCRAC), los propietarios de tierras pueden ser responsables por las fugas en tanques que han sido abandonados en sus propiedades por dueños anteriores.

Consecuentemente, los compradores deben inspeccionar cuidadosamente la propiedad antes de la compra. (ver las secciones Auditorias Ambientales y secciones de la $A R C R A C$ ). Si la fugas de tanques son descubiertas, la limpieza puede ser supervisada por los propietarios de la tierra o por la APA. Esto será inevitablemente muy costoso.

\section{Fuentes}

Estatutos de Florida, Capitulo 376; Titulo 62 Código Administrativo de Florida.; Código 40 de las Regulaciones Federales secciones 280 y 281. 
Manual de los Reglamentos del Agua de Florida: Sistemas de Tanques de Almacén de.... 4

Contactos de Información

S-2, L-4, F-3, F-4 